\title{
Aesthetics in Human-Computer Interaction: Views and Reviews
}

\author{
Salah Uddin Ahmed ${ }^{1}$, Abdullah Al Mahmud ${ }^{2}$, and Kristin Bergaust ${ }^{3}$ \\ ${ }^{1}$ Department of Computer and Information Science, \\ Norwegian University of Science and Technology, Trondheim, Norway \\ ${ }^{2}$ Department of Industrial Design, \\ Eindhoven University of Technology, The Netherlands \\ ${ }^{3}$ Faculty of Art, Design and Drama, \\ Oslo University College, Norway \\ salah@idi.ntnu.no, a.al-mahmud@tue.nl, kristin@anart.no
}

\begin{abstract}
There is a growing interest of aesthetics issues in Human-Computer Interaction (HCI) in the recent days. In this article we present our literature review where we investigate where and how aesthetics has been addressed by the HCI researchers. Our objective is to find out the sectors in HCI where aesthetics has a role to play. Aesthetics in HCI can be the common interest that involves both art and technology in HCI research to facilitate from each others discipline in the form of mutual interaction.
\end{abstract}

Keywords: Aesthetics, interaction, usability, art and technology.

\section{Introduction}

Interaction with computer addresses many issues such as ergonomics, design, human factors, usability, aesthetics and so on. Interaction includes the main interface with which human communicates with computer. Thus it is one of the most potential sectors in computing where aesthetics is applicable. As the technology advances and the processing power of computers increases along with the reduced memory cost, the user interfaces of applications are getting richer with much more details including aesthetics elements that enhance the user experiences.

In this article we present our literature review where we investigate where and how aesthetics has been addressed by the Human Computer Interaction (HCI) researchers. Our objective is to find the sectors of common interest between artists and technologists and improve collaboration between them to facilitate from each other's background knowledge and skills in the form of a mutual symbiosis. An important topic in $\mathrm{HCI}$, aesthetics, however is an abstract concept and is used in a wide range of contexts in association with other words denoting varying meanings. Even in art and humanities discipline the word is used in various contexts and hence it is understandable that researchers in technology and computing might use the word incoherently. Besides, there are also different views on applying aesthetics in human computer interaction. In this article we would like to present from the literature how the word 
aesthetics has been used by the researchers, which contexts it is used and what meaning it is used for. We would like to categorize the field of human computer interaction into some clusters of thematic areas in order to understand how the field looks like when we view it from the point of aesthetics. The objective is to understand the meaning of aesthetics, remove confusions and understand the use, applications and possibilities of aesthetics in the context of human computer interaction.

The use of aesthetics in computing specially in human computer interaction is getting lot of attention in the recent days. Call for paper of CHI 2008 (conference on Human Factors in Computing Systems) with a slogan, "Art, Science, Balance" reveals how the influence of aesthetics and art in general is well recognized by the research community recently. But as the area is still very new and as HCI researchers are not experts on arts and aesthetics there is room for misunderstanding. Therefore an investigation of our current understanding and a snapshot of the field viewed from the perspective of aesthetics will help the researchers to better understand the position and role of aesthetics in human computer interaction. Besides aesthetics being a link between technology and art will help future researchers to open up more possibilities of collaboration between art and human computer interaction.

The rest of the paper is organized as follows. Section 1.1 presents our research background and section 1.2 describes the research method. Section 2 gives definitions of aesthetics and its importance in HCI. Section 3 provides the result of the review. Section 4 concludes the paper with discussion and our viewpoints reflecting the result obtained from the review.

\subsection{Research Background}

The research is conducted as part of the SArt project [1] inside the Software Engineering group at the Department of Computer Science in the Norwegian University of Science and Technology. Our ultimate objective is to propose, assess, and improve methods, models, and tools for software development in art context while facilitating collaboration with artists. As part of research in SArt we have performed a literature review in order to conceptualize the intersection of software and art [2]. From the review we have discovered that the intersection involves people from diverse background and interest, for example art critics, software developers, educators and so on. This is also visible in the software dependent art projects that SArt group members have participated. From our experience of working with artists we have seen that technologists and artists have different viewpoints. While working with artists we have observed that there is a difference in the way how artists and technologists work as well as differences in how the make meanings of different concepts. In a field where there are both technologists and artists involved there are many issues that has to be considered such as having a common language, good collaboration, coexistence of artistic process and technical process, evaluation of products both from technical and aesthetic viewpoint etc. This work is in line with our investigation of how we can improve the collaboration between artists and technologists by working together and learning from each other. As a part of that goal here we would like to look into the field of human computer interaction to see how aesthetics, a concept from arts has 
been applied by the technologists to discover the field from artists' and technologists' common interest where aesthetics is the bridge between them.

\subsection{Research Method}

We followed a systematic review of the literature published in recent conference proceedings and journals which are easily accessible from ACM, IEEE and Springer digital library. We started the review by following Kitchenham's principles [3]. At the beginning, we selected papers by reading the titles and abstracts, later we have modified the process as we could not find lot of papers by only title and abstracts. We searched the entire article with the keyword search and if a match was found we read the abstract and part of the article that has the keyword. We discarded articles that has only mentioned the word merely and has no significant meaning or relationship between aesthetics and the main work of the paper. Otherwise we read the full article and listed in our final selection. A total of 67 papers were selected from the following top-level conference proceedings limited with the years mentioned below:

- Conference on Human Factors in Computing Systems CHI - Years (from 2008 to 1997)

- Conference on Designing Pleasurable Products and Interfaces, DPPI - Years (2007, 2005, 2003)

- DIS conferences - with no time limits

- TOCHI - with no time limits

- NordiCHI and HCII - with no time limits

The keywords that we have used are a. aesthetics b. aesthetic. We have chosen both 'aesthetics' and 'aesthetic' in order not to miss the mentions of word such as aesthetically.

\section{Aesthetics and HCI}

New conferences and workshops that explore various aspects of the consequences of the integration of computing into everyday life are emerging. New terms are entering the HCI vocabulary such as emotion, pleasure, experience, expression, and indeed aesthetics. Aesthetics is increasingly viewed as a key issue with respect to interactive technology. But aesthetics is a general term and it is often used in association with other terms. Here we present what it actually means and how it is defined.

The Oxford English Dictionary presents the following definitions for aesthetics: i) the science that treats the conditions of sensuous perception; and ii) the philosophy or theory of taste, or of the perception of the beautiful in nature and art [4]. In the preface of Encyclopedia of Aesthetics which is one of the most comprehensive references on this topic, Kelly states [5], "Ask contemporary aestheticians what they do, however, and they are likely to respond that aesthetics is the philosophical analysis of the beliefs, concepts, and theories implicit in the creation, experience, interpretation, or critique of art." Britannica encyclopedia defines it as philosophical study of the qualities that make something an object of aesthetic interest and of the nature of aesthetic 
value and judgment [6]. To define its subject matter more precisely is, however, very difficult. It also mentions that self-definition could be said to have been the major task of modern aesthetics.

\subsection{Why Aesthetics}

Human computer interaction started from computing field and now extending its scope in many other directions by including behavioral science, psychology, and sociology and so on. However, there are allegations that human technology interaction has focused almost exclusively in goal driven behavior in all work settings [7]. However, since computing expands its domain from workplace to pervasive and domestic environments, interest in aesthetics for designing is increasing in HCI. Gaver and Martin suggests that the importance of non-instrumental user needs, such as surprise, diversion, or intimacy should be addressed by technology [8]. Jordan proposed a hierarchy of such needs and claimed that - along with the functionality and usability of a system - different aspects of pleasure are important to enhance the user's interaction with it [9].

\subsection{Types of Aesthetics}

In the context of HCI two types of aesthetics are mentioned in [10], classical aesthetics and expressive aesthetics. Classical aesthetics refer to traditional notions emphasizing orderly and clear design and expressive aesthetics to designs creativity and originality. Study shows that classical aesthetics is perceived more evenly by users whereas expressive aesthetics can vary depending on framing effects or different cultural and contextual stimuli [7].

Different kinds of quality dimensions are mentioned such as Ergonomic, Hedonic, Instrumental and Non-instrumental. Ergonomic quality comprises quality dimensions that are related to traditional usability, i.e. efficiency and effectiveness [11]. Hedonic quality comprises quality dimensions with no obvious relation to the task the user wants to accomplish with the system, such as originality, innovativeness, beauty etc. In other place, instrumental Quality and Non instrumental Quality is used in relation to perception of user experience which are basically the same as ergonomic and hedonic qualities [7].

\section{Aesthetics in Human-Computer Interaction}

Aesthetics come into play in many stages in many ways in HCI. In this section we would like to present the different areas and contexts where aesthetics is mentioned and addressed in our reviewed literature. From the review, we have identified some of the areas where aesthetics is used in HCI. Some of the key areas that we have identified are: Artifacts design, System design, Attractiveness and look and feel of User Interface (UI), Interaction with a system, Usability and user experience, Research methods for HCI. The following table lists the articles according to the particular addressed themes or areas of HCI. 
Table 1. Thematic subject areas where aesthetics has been addressed in HCI literature

\begin{tabular}{lll}
\hline Themes & \multicolumn{1}{c}{ Articles } & \multicolumn{1}{c}{ What is addressed } \\
\hline Artifacts Design & {$[12],[13],[14]$,} & $\begin{array}{l}\text { Design of artifacts and gadgets, evaluation of } \\
\text { artifacts, environment related design of artifacts } \\
\text { (ubiquitous computing). }\end{array}$ \\
& {$[15],[8],[16],[17]$} & $\begin{array}{l}\text { Software applications, tools, artistic software, } \\
\text { games. }\end{array}$ \\
\hline System Design & {$[17],[11],[18]$,} \\
& {$[19],[17]$} & $\begin{array}{l}\text { User interface of an application, mobile phone, } \\
\text { web sites etc. }\end{array}$ \\
\hline $\begin{array}{l}\text { Attractiveness and } \\
\text { Look and Feel of UI }\end{array}$ & {$[20],[21],[22]$} \\
\hline $\begin{array}{l}\text { Interaction with a } \\
\text { system }\end{array}$ & {$[26],[27],[25]$} & Interactive art installations, museum guide, \\
\hline $\begin{array}{l}\text { Usability and User } \\
\text { Experience }\end{array}$ & {$[12],[29],[30],[27],[31]$,} & Users' feelings, emotion, usability. \\
\hline $\begin{array}{l}\text { HCI Research } \\
\text { methods }\end{array}$ & {$[32],[25]$} & Research methods that considers aesthetics. \\
\hline
\end{tabular}

\subsection{Artifact Design}

With the recent shift from narrow focus on work to a broader view of interaction industrial designers, communication designers, and newly minted interaction designers all began to play more important roles in the invention and development of new artifacts meant to address a broad set of problems and opportunities [14]. Future Information appliances design may benefit from considering aesthetics aspects of the gadgets [8]. How digital technologies might be employed in everyday settings can combine concepts from both work and plays and these devices often act not only as an emulator or information source instead creates a new form of appreciation both conceptual and aesthetic [16]. Often these devices are created by artists and are displayed as interactive and or digital art in the art galleries.

Evaluation of Artifacts. Aesthetics is not only an issue during the design of these diverse computing devices/artifacts but also in the evaluation of these devices. After running a survey on heuristic evaluation match between design of ambient display and environments in [35], the authors assert, "The display should be pleasing when it is placed in the intended setting."

Ubiquitous Computing. Areas such as ubiquitous computing, augmented reality, and physical computing have made it evident that the personal computer is just one out of many possible ways in which we can design how humans interact with computers [12]. The design of these devices should be carefully done so that they consider the contextual qualities of the environment such as aesthetics, emotions and aspirations whether they are place indoor in home, museums or outdoor in public places [15] [36] [34]. For example, when designing an ambient display, one should notice an ambient display because of a change in the data it is presenting and not because its design clashes with its environment [35]. 


\subsection{System Design}

By system design, we mean the context of creating new tools or software applications. Hedonic quality plays a substantial role in forming users judgment of appeal and it should be explicitly taken into account when designing a software system [11]. In [17], authors presented a technique used for creating a new kind of tool for 3D drawing. In creative settings where innovation and novelty is sought, artists and technologists work together in close collaboration.

\subsection{Attractiveness and Look and Feel of UI}

Aesthetics has been addressed by many articles in the attractiveness and look and feel of different websites. There is already a transition towards aesthetically pleasing interfaces and it will continue as more importance is placed on the aesthetics of a user interface, and as the proper tools are available to interface designers for creating such interfaces [20]. A theoretical framework for assessing the attractiveness of web sites has been introduced in [22] where as aesthetics is considered an issue for rating web sites in [23]. Aesthetic factors beyond usefulness and traditional usability are increasingly recognized as contributing to the overall success of a product or system [24] [25].

\subsection{Interacting with a System}

Aesthetics and interaction are interwoven concepts, rather than separate entities [26]. In aesthetics of interaction the emphasis shifts from an aesthetically controlled appearance to an aesthetically controlled interaction, of which appearance is a part. Aesthetics of interaction moves the focus from ease of use to enjoyment of the experience [27].

Mixed Reality and Virtual Reality. Design for mixed reality or virtual reality devices are driven by many contextual requirements of which aesthetics is an important part [36]. Artistic association is also important in virtual reality systems, "The curtain rain was chosen for its aesthetic qualities, both in terms of its striking visual image and sound, its asymmetric transparency, and not least, due to the artistic association of projecting a virtual desert into a curtain of water" [19].

Interactive Art. Interactive art is a new kind of art that is highly dependent on technology and user interaction. Often these kinds of artworks are illustration of interdisciplinary collaboration between research, design, craft and art and involve interaction with the user in a new or innovative way such as presented in the case of computational composite [12] or computational textile kit in [29]. In [28], the authors present a method developed to support design of innovative interactive technology.

\subsection{Usability and User Experience}

The use of aesthetics is not always warmly accepted by HCI researchers. In fact, as mentioned in [37], it is often seen by many professionals as inversely proportional to easiness of use or usability. There has been continuous debate on conflicting impact of usability and aesthetics in HCI [38]. However, later many researchers worked on 
the positive impact of aesthetics. Now empirical evidence shows correlations between the perceived aesthetic quality of a system's user interface and overall user satisfaction [31], [32] leading to claims that aesthetic design can be a more important influence on users' preference than traditional usability [25]. Usability is important but good aesthetic design can overcome some deficit of usability problems. In fact, usability and user experience is related to the appraisal of a system which depends on both instrumental and non instrumental qualities [7].

\subsection{HCI Research Methods}

HCI has emerged as a design-oriented field of research, directed at large towards innovation, design, and construction of new kinds of information and interaction technology. Three accounts have been named regarding the design theory such as the conservative account, the romantic account, and the pragmatic account of which pragmatic account is the one that considers the issues such as creativity, craft, aesthetics [33]. HCI researchers have adopted approaches based on traditions of artistdesigners. Thus new methods have been developed in HCI such as cultural probes whose purpose is to inspire the creation of appropriate pleasurable even provocative designs [39].

\section{Discussions and Conclusion}

From the review we have seen where and how aesthetics has been used in context of HCI. The outcome reveals us a picture of the relationship between aesthetics and HCI The consideration of aesthetics is visible in many sectors of HCI, from artifact design to research methods for collecting user data or evaluating artifacts. What we see from the review is that the most common use of aesthetics in HCI refers to visual aesthetics or expressive aesthetics. The conflict with usability also accounts in case of expressive aesthetics. We believe that the contradiction arose since we referred to only visual or expressive aesthetics and compared its effects with usability. But aesthetics as a philosophy is a wide concept rather than only the visual or static beauty of interfaces. It refers to the feelings associated with the use and interaction with a system. In this case aesthetics of interaction is not conflicting with usability; rather usability is a part of aesthetics of interaction. Having high expressive aesthetics and less usability can affect the emotion of the user negatively, thus the aesthetics of interaction. So proper aesthetics of interaction should define where and how expressive aesthetics will be included and how much they will act aligned with usability, and overall user experience of the user effecting their emotion positively.

In this paper, we have put together different contexts of use of aesthetics in HCI to present the reader different meanings and views that we attach with aesthetics in HCI. As technology will advance giving us more options to use more expressive and innovative interaction with computers, aesthetics in HCI will get even more attention in the future. Proper understanding of the meaning, value and impact would help the future researchers to be more conscious about the role of aesthetics and possibly eliminate confusions around it among them. Aesthetics can in that way bring together 
artists, designers and technologists with creativity, inspiration and engagement in a collaborative and multidisciplinary milieu inside human computer interaction.

\section{References}

1. SArt Project, at Norwegian University of Science and Technology, http://prosjekt.idi.ntnu.no/sart/

2. Ahmed, S.U., J.L., Trifonova, A., Sindre, G.: Conceptual framework for the intersection of software and art. In: Braman, J., Vincenti, G., Trajkovski, G. (eds.) Handbook of Research on Computational Arts and Creative Informatics, Information Science Reference (2009)

3. Kitchenham, B.: Procedures for Performing Systematic Reviews. Keele University Technical Report TR/SE-0401 and NICTA Technical Report 0400011T.1 (2004)

4. Oxford English Dictionary, http: / / www . oed. com/

5. Kelly, M. (ed.): Preface to Encyclopedia of Aesthetics, vol. 1. Oxford University Press, New York (1998)

6. Encyclopedia Britannica, http: / / www.britannica.com

7. Mahlke, S., Thüring, M.: Studying antecedents of emotional experiences in interactive contexts. In: Proceedings of the SIGCHI conference on Human factors in computing systems. ACM, San Jose, California, USA (2007)

8. Gaver, B., Martin, H.: Alternatives: exploring information appliances through conceptual design proposals. In: Proceedings of the SIGCHI conference on Human factors in computing systems, pp. 209-216. ACM, The Hague, The Netherlands (2000)

9. Jordan, P.W.: Designing pleasurable products. Taylor \& Francis, London (2000)

10. Hartmann, J., Angeli, A.D., Sutcliffe, A.: Framing the user experience: information biases on website quality judgement. In: Proceeding of the twenty-sixth annual SIGCHI conference on Human factors in computing systems, pp. 855-864. ACM, Florence, Italy (2008)

11. Hassenzahl, M., Platz, A., Burmester, M., Lehner, K.: Hedonic and ergonomic quality aspects determine a software's appeal. In: Proceedings of the SIGCHI conference on Human factors in computing systems, pp. 201-208. ACM, The Hague, The Netherlands (2000)

12. Vallgårda, A., Redström, J.: Computational composites. In: Proceedings of the SIGCHI conference on Human factors in computing systems, pp. 513-522. ACM, San Jose, California, USA (2007)

13. Lehn, D.: Engaging constable: revealing art with new technology. In: Proceedings of the SIGCHI conference on Human factors in computing systems, pp. 1485-1494. ACM, San Jose, California, USA (2007)

14. Zimmerman, J., Forlizzi, J., Evenson, S.: Research through design as a method for interaction design research in HCI. In: Proceedings of the SIGCHI conference on Human factors in computing systems, pp. 493-502. ACM Press, San Jose, California, USA (2007)

15. Tolmie, P., Pycock, J., Diggins, T., MacLean, A., Karsenty, A.: Unremarkable computing. In: Proceedings of the SIGCHI conference on Human factors in computing systems: Changing our world, changing ourselves, pp. 399-406. ACM Press, Minneapolis, Minnesota, USA (2002)

16. Gaver, W., Boucher, A., Law, A., Pennington, S., Bowers, J., Beaver, J., Humble, J., Kerridge, T., Villar, N., Wilkie, A.: Threshold devices: looking out from the home. In: Proceeding of the twenty-sixth annual SIGCHI conference on Human factors in computing systems, pp. 1429-1438. ACM, Florence, Italy (2008) 
17. Schkolne, S., Pruett, M., Schröder, P.: Surface drawing: creating organic 3D shapes with the hand and tangible tools. In: Proceedings of the SIGCHI conference on Human factors in computing systems, pp. 261-268. ACM, Seattle, Washington, United States (2001)

18. Santella, A., Agrawala, M., DeCarlo, D., Salesin, D., Cohen, M.: Gaze-based interaction for semi-automatic photo cropping. In: Proceedings of the SIGCHI conference on Human Factors in computing systems, pp. 771-780. ACM, Montréal, Québec, Canada (2006)

19. Koleva, B., Taylor, I., Benford, S., Fraser, M., Greenhalgh, C., Schnädelbach, H., Lehn, D.v., Heath, C., Row-Farr, J., Adams, M.: Orchestrating a mixed reality performance. In: Proceedings of the SIGCHI conference on Human factors in computing systems, pp. 3845. ACM, Seattle, Washington, United States (2001)

20. Grossman, T., Kong, N., Balakrishnan, R.: Modeling pointing at targets of arbitrary shapes. In: Proceedings of the SIGCHI conference on Human factors in computing systems, pp. 463-472. ACM, San Jose, California, USA (2007)

21. Consolvo, S., McDonald, D.W., Toscos, T., Chen, M.Y., Froehlich, J., Harrison, B., Klasnja, P., LaMarca, A., LeGrand, L., Libby, R., Smith, I., Landay, J.A.: Activity sensing in the wild: a field trial of ubifit garden. In: Proceeding of the twenty-sixth annual SIGCHI conference on Human factors in computing systems, pp. 1797-1806. ACM, Florence, Italy (2008)

22. Hartmann, J., Sutcliffe, A., Angeli, A.D.: Investigating attractiveness in web user interfaces. In: Proceedings of the SIGCHI conference on Human factors in computing systems, pp. 387-396. ACM, San Jose, California, USA (2007)

23. Ivory, M.Y., Hearst, M.A.: Statistical profiles of highly-rated web sites. In: Proceedings of the SIGCHI conference on Human factors in computing systems: Changing our world, changing ourselves, pp. 367-374. ACM, Minneapolis, Minnesota, USA (2002)

24. Green, W.S., Jordan, P.W.: Pleasure With Products: Beyond Usability. Taylor and Francis, New York (2002)

25. Norman, D.A.: Emotional Design: Why We Love (Or Hate) Everyday Things Basic Books (2003)

26. Djajadiningrat, W., Gaver, W., Fres, J.W.: Interaction Relabelling and Extreme Characters: Methods for Exploring Aesthetic Interactions. In: Proceedings of the conference on Designing interactive systems: processes, practices, methods, and techniques (2000)

27. Isbister, K., Höök, K., Sharp, M., Laaksolahti, J.: The sensual evaluation instrument: developing an affective evaluation tool. In: Proceedings of the SIGCHI conference on Human Factors in computing systems, pp. 1163-1172. ACM, Montréal, Québec, Canada (2006)

28. Ljungblad, S., Holmquist, L.E.: Transfer scenarios: grounding innovation with marginal practices. In: Proceedings of the SIGCHI conference on Human factors in computing systems, pp. 737-746. ACM, San Jose, California, USA (2007)

29. Buechley, L., Eisenberg, M., Catchen, J., Crockett, A.: LilyPad Arduino: using computational textiles to investigate engagement, aesthetics, and diversity in computer science education. In: Proceeding of the twenty-sixth annual SIGCHI conference on Human factors in computing systems, pp. 423-432. ACM, Florence, Italy (2008)

30. Tohidi, M., Buxton, W., Baecker, R., Sellen, A.: Getting the right design and the design right. In: Proceedings of the SIGCHI conference on Human Factors in computing systems, pp. 1243-1252. ACM, Montréal, Québec, Canada (2006)

31. Tractinsky, N., Katz, A.S., Ikar, D.: What is beautiful is usable. J. Interacting with Computers 13, 127-145 (2000)

32. Lindegaard, G., Dudek, C.: What is this evasive beast we call user satisfaction? J. Interacting with Computers 15, 429-452 (2003) 
33. Fallman, D.: Design-oriented human-computer interaction. In: Proceedings of the SIGCHI conference on Human factors in computing systems, pp. 225-232. ACM, Ft. Lauderdale, Florida, USA (2003)

34. Ballegaard, S.A., Hansen, T.R., Kyng, M.: Healthcare in everyday life: designing healthcare services for daily life. In: Proceeding of the twenty-sixth annual SIGCHI conference on Human factors in computing systems, pp. 1807-1816. ACM, Florence, Italy (2008)

35. Mankoff, J., Dey, A.K., Hsieh, G., Kientz, J., Lederer, S., Ames, M.: Heuristic evaluation of ambient displays. In: Proceedings of the SIGCHI conference on Human factors in computing systems, pp. 169-176. ACM, Ft. Lauderdale, Florida, USA (2003)

36. Schnädelbach, H., Koleva, B., Flintham, M., Fraser, M., Izadi, S., Chandler, P., Foster, M., Benford, S., Greenhalgh, C., Rodden, T.: The augurscope: a mixed reality interface for outdoors. In: Proceedings of the SIGCHI conference on Human factors in computing systems: Changing our world, changing ourselves, pp. 9-16. ACM, Minneapolis, Minnesota, USA (2002)

37. Karvonen, K.: The beauty of simplicity. In: Proceedings on the 2000 conference on Universal Usability, ACM, Arlington, Virginia, United States (2000)

38. Norman, D.A.: The Design of Everyday Things. MIT Press, London (1998)

39. Wolf, T.V., Rode, J.A., Sussman, J., Kellogg, W.A.: Dispelling "design" as the black art of CHI. In: Proceedings of the SIGCHI conference on Human Factors in computing systems, pp. 521-530. ACM, Montréal, Québec, Canada (2006) 